\title{
Cross-sectional study of quality of life impairment of adult female acne patients
}

\author{
Ehiaghe L Anaba, Motunsope Olufolakemi Cole-Adeife \\ Department of Medicine, Lagos State University Teaching Hospital, Lagos, Nigeria
}

\begin{abstract}
The effect of acne vulgaris on the quality of life of adult females is not readily documented nor the factors that impair quality of life in these adult females. The aim of this study was to document quality of life impairment and the factors that affect this quality of life in adult female acne patients. The study was a prospective cross sectional study of 56 adult female acne patients aged 25 years and above. Socio-demographic data, clinical examination were documented with a study proforma. Quality of life was assessed using Cardiff Acne Disability Index (CADI). Data was
\end{abstract}

Correspondence: Anaba L Ehiaghe. Department of Medicine, Lagos State University Teaching Hospital, 1-5 Oba Akinjobi Way, Ikeja, Lagos, Nigeria.

Tel.: +2348030495911

E-mail: ehianaba@yahoo.com

Key words: Acne; adult female; quality of life; adult female acne.

Contributions: ELA: Conceptualization, patient review, questionnaire design, manuscript writing and review. MOCA: Patient review, case records retrieval and documentation, questionnaire design, manuscript review.

Conflict of interest: The authors declare no conflict of interest.

Availability of data and materials: All data generated or analyzed during this study are included in this published article.

Ethics approval and consent to participate: The Ethics Committee of INSTITUTION approved this study (LREC.06/10/967). The study is conformed with the Helsinki Declaration of 1964, as revised in 2013, concerning human and animal rights. All patients participating in this study signed a written informed consent form for participating in this study.

Informed consent: Written informed consent was obtained from a legally authorized representative(s) for anonymized patient information to be published in this article.

Received for publication: 2 March 2021.

Revision received: 30 May 2021.

Accepted for publication: 10 June 2021.

This work is licensed under a Creative Commons Attribution NonCommercial 4.0 License (CC BY-NC 4.0).

${ }^{\circ}$ Copyright: the Author(s), 2021

Licensee PAGEPress, Italy

Annals of Clinical and Biomedical Research 2021; 2:135

doi:10.4081/acbr.2021.135 analysed using SPSS version 22. Mean of independent groups were compared using Students ' $t$ ' test while Chi squared test was used to compare categorical variables. For all statistical tests, P value $<0.05$ was adjudged to be significant. The mean age of the participants was $33.4 \pm 8.2$ and mean CADI was $6.6 \pm 3.8$, minimum CADI was 2 and maximum was 15. Quality of life impairment was mild, moderate and severe in $35.7 \%, 37.5 \%$ and $26.8 \%$ respectively. The items affected in the CADI index were questions about "Perception of how bad pimples were," "Feelings about appearance of skin," and "Aggression, frustration and embarrassment." Factors associated with quality of life impairment were age, post inflammatory hyperpigmentation, presence of scarring. Quality of life is impaired by acne in adult females. This impairment is made worse by age, presence of scarring and post-inflammatory hyperpigmentation and not marital status, level of education and a family history of acne.

\section{Introduction}

Increasingly, adult females are presenting with acne vulgaris with almost $40 \%$ of women affected. ${ }^{1}$ Studies on Quality of Life (QoL) in Adult Female Acne (AFA) patients are rare but the few studies conducted show AFA to adversely affect all aspects of QoL of adult females resulting in a low self-esteem, negative perception and discrimination at work. ${ }^{2-4}$ Adult female acne and it's treatment is associated with quality of life impairment and this is often ignored. ${ }^{2,3}$ The impact of acne upon QoL is a very important component of the overall morbidity associated with acne and reducing the psychosocial impact of acne is now considered one of the clinical principles of management.

Adult female acne results in decreased social functioning, negative emotions about having to be treated for acne and a low selfesteem. ${ }^{3,4}$ Acne confers a worse QoL in adult females than in adolescents who have acne. ${ }^{5}$ Age at onset, occupation, marital status, duration of acne, location of lesions, previous treatment and change in severity of acne following treatment have not been found to impact on adult female QoL. ${ }^{2,6}$ However, a family history of acne, treatment of acne affect QoL in adult females. ${ }^{2,6}$ Age on the other hand appears to affect QoL negatively in India but not in Germany. 2,6

In adult females, post inflammatory hyperpigmentation irrespective of its severity impacts negatively on QoL. ${ }^{7,8}$ Skroza et al. in a study of 1167 adult and teenage acne patients found that, the female gender had a worse QoL irrespective of age but Gupta et al. came to a contrary conclusion. ${ }^{6,9}$ Grupta et al. found no effect of gender on $\mathrm{n}$ QoL impairment. ${ }^{6}$ These studies may have come to different conclusions because of the differing population studied.

Measuring the impact of acne on quality of life allows us to understand the disease from the patient's point of view. Patient management now includes considerations of the effect of acne and its treatment and what patients feel or think about their acne. 
However, documentations on QoL in acne currently, is mostly on adolescent acne despite the rising incidence of adult females presenting with acne..$^{10,11}$ Hence, the aim of this study is to; determine the QoL of these adult female acne patients, determine the factors that affect the QoL in these females (level of education, presence of scars, type of scars, age, marital status, age at onset of acne and family history of acne). Also, to determine the specific items impaired in the CADI QoL instrument.

\section{Materials and Methods}

A prospective cross-sectional study was conducted on all 56 adult females aged 25 years and above who presented with acne during the study period following ethical approval from the hospital's ethical review board. The study was conducted from February 2018 to January 2019 at the out-patient dermatology clinic of the Lagos state university teaching hospital, Lagos, Nigeria.

The subject's socio-demographic parameters (level of education, age, marital status, age at onset of acne and duration of acne) and clinical evaluation (severity of acne, presence and type of scars,) was documented using a data collection proforma. The proforma was self-administered but where clarification of any question was sort, subjects were assisted to ensure proper and adequate filling of the proforma.

A full clinical examination to assess for facial acne vulgaris and its severity was carried out by the researchers. Acne was graded based on the comprehensive acne grading scale into mild, moderate and severe. ${ }^{12}$ Quality of life was assessed using the Cardiff Acne Disability Index (CADI). ${ }^{13,14}$

The CADI is a disease specific instrument for acne and it is made up of five (5) questions and four responses. The five questions relate to feeling of aggression, frustration, interference with social life, avoidance of public changing facilities and appearance of the skin (all over the last month) and an indication of how bad the acne is now. Scores range from 0-3 per question. This leads to scores of $0-15$, with high scores inferring poor QoL and low scores little or no impairment of QoL. The CADI is interpreted as follows; CADI scores of $<4$ is interpreted as mild, scores of 5-9 as moderate and scores of 10-15 as severe impairment of QoL. ${ }^{15}$

The Statistical Package for Social Sciences (SPSS) IBM version 22 was used to enter and analyze the data. Percentages, mean and standard deviation of numerical variables was determined. Histogram plot was used to assess if the outcome variable (quality of life scores) was normally distributed. Mean of independent groups were compared using Students ' $t$ ' test while Chi squared test was used to compare categorical variables. For all statistical test $p$ value $<0.05$ was adjudged to be significant. Microsoft excel was used to draw charts

\section{Results}

Fifty-six treatment naïve adult female acne patients participated in this study. The mean age of the participants was $33.4 \pm 8.2$ (age range; 25-67 years) and mean age at onset of acne was $21.9 \pm 10.7$. Level of education was tertiary in $87.5 \%$, secondary in $8.9 \%$ and primary in $3.6 \%$. Marital status was single, married and

Table 1. Clinical and sociodemographic details of respondents.

\begin{tabular}{lc} 
Variable & N(\%) \\
Age group (years) & \\
$<30$ & $21(37.5)$ \\
$30-39$ & $24(42.9)$ \\
$40-49$ & $9(16.1)$ \\
$\geq 50$ & $2(3.6)$ \\
Age at onset of acne (years) & \\
$<20$ & $30(53.6)$ \\
$20-29$ & $16(28.6)$ \\
$30-39$ & $5(8.9)$ \\
$\geq 40$ & $5(8.9)$ \\
\hline History of acne as a teenager & \\
Yes & $35(62.5)$ \\
No & $21(37.5)$ \\
Anatomical site & \\
Face only & $45(80.3)$ \\
Face and other sites & $11(19.6)$ \\
\hline Post inflammatory hyperpigmentation & \\
Yes & $48(85.7)$ \\
No & $8(14.3)$ \\
Presence of scarring & \\
Yes & $49(87.5)$ \\
No & $7(12.5)$ \\
\hline Severity of Acne & \\
Mild & $11(19.6)$ \\
Moderate & $25(44.6)$ \\
Severe & $20(35.8)$ \\
\hline
\end{tabular}

Table 2. Cadiff acne disability index.

\begin{tabular}{|c|c|}
\hline Index parameter & $N(\%)$ \\
\hline $\begin{array}{l}\text { Aggression, frustration and embarrassment In the last month } \\
\text { Not at all } \\
\text { Yes }\end{array}$ & $\begin{array}{l}14(25.0) \\
42(75.0)\end{array}$ \\
\hline $\begin{array}{l}\text { Interference with social life, social events or relationships with opposite sex } \\
\text { Not at all } \\
\text { Yes }\end{array}$ & $\begin{array}{l}31(55.4) \\
25(44.6)\end{array}$ \\
\hline $\begin{array}{l}\text { Avoided public changing facilities, or wearing spaghetti hand blouses and singlets because of pimples } \\
\text { Not at all } \\
\text { Yes }\end{array}$ & $\begin{array}{l}41(73.2) \\
15(26.8)\end{array}$ \\
\hline $\begin{array}{l}\text { Feelings about appearance of skin over the last month } \\
\text { Not bothered } \\
\text { Bothered }\end{array}$ & $\begin{array}{c}3(5.4) \\
53(94.6)\end{array}$ \\
\hline $\begin{array}{l}\text { Perception of how bad pimple were } \\
\text { Not a problem } \\
\text { A problem }\end{array}$ & $\begin{array}{c}0(0.0) \\
56(100.0)\end{array}$ \\
\hline
\end{tabular}


widowed in $64.3 \%, 33.9 \%$ and $1.8 \%$ respectively. A family history of acne was yes, no and I don't know in 51.8\%, 26.8\% and $21.6 \%$ respectively. The duration of acne was $<1$ year, 1-2 years, 3-4 years and $\geq 5$ years in $14.3 \%, 16.1 \%, 5.4 \%$ and 64.3 respectively. Over eighty percent had post acne scar and this was post inflammatory in $85.7 \%$ (Table 1).

Quality of life was impaired in all the participants (100\%). Mean CADI was $6.6 \pm 3.8$, minimum CADI was 2 and maximum was 15 . Quality of life impairment was mild, moderate and severe in $35.7 \%, 37.5 \%$ and $26.8 \%$ respectively. The items affected in the CADI index were questions about "Perception of how bad pimples were," "Feelings about appearance of skin," and "Aggression, frustration and embarrassment" (Table 2).

Significantly associated factors with QoL impairment were age, post-inflammatory hyperpigmentation and presence of scarring. Marital status, $\mathrm{P}=0.200$, severity of acne, $\mathrm{P}=0.670$, duration of acne, $\mathrm{P}=0.072$ and age at onset of acne, $\mathrm{P}=0.295$ did not significantly affect QoL (Table 3).

\section{Discussion}

AFA is a new concept in dermatology with the increasing presentation of acne in adult females. ${ }^{1}$ The cause and risk factors for AFA have remained unclear but cosmetics, smoking, family history of acne and a history of teenage acne are suggested. ${ }^{16}$ Quality of life (QoL) affectation studies of AFA are few compared to QoL studies of adolescent acne. ${ }^{2,10,11}$ A study comparing QoL between adolescents and adult females who have acne, reveal a worse QoL impairment in adult females. ${ }^{5}$

Quality of life was impaired in all the participants this study and their mean CADI was also high. This QoL impairment we believe may have been for a number of reasons. This study had a high percentage of females with a history of teenage acne. The recurrent nature of teenage acne and its attendant treatment difficulties may have contributed to their impaired QoL. Also, these were highly educated females who may have read up on the chronicity of acne with its attendant resistance to treatment as documented by Dreno et al. in their review of AFA. ${ }^{1}$ Furthermore, embarrassment from the recurrence of a teenage problem, comments from colleagues and partners could have influenced their QoL. This study result is in consonance with studies by Gupta et al who reported a similar mean CADI as this study. ${ }^{6}$

The level of QoL impairment was mild to moderate despite the impairment of QoL in all the participants. Quality of life is a subjective assessment by the individuals affected by a particular disease making level of impairment unpredictable. The level of QoL impairment may be due to the severity of acne in the participants being mostly mild to moderate. Reports from other studies of QoL impairment in AFA show a similar level of impairment as the participants in this study. ${ }^{6}$

Specific item affectation on the CADI were questions about: perception of how bad pimples were, feelings about appearance of skin, and aggression, frustration and embarrassment. Majority of the participants felt embarrassed and frustrated. These emotions could be as a result of the cosmetic age we live in now where television adverts and personal desires contribute to a need for perfect and flawless face. Also, frequent clinic attendance, treatment protocols and the chronicity of acne would have contributed to their frustration. Furthermore, embarrassment may have been caused by the presence of the acne lesions and comments from friends. Embarrassment from having acne is commonly documented like in our study in adults. 6,8

All the participants perceived their acne to be a problem. Severity of acne in this study was moderate to severe, scarring especially post inflammatory hyperpigmentation was prominent in this study making the perception of acne to be a problem. On how they felt about the appearance of their skin, despite reporting the acne to be a problem, participants were not bothered about the appearance of their skin. This was surprising especially as acne was on the face and visible to all. They may not have been bothered since they were expecting to be treated with clearance of the acne lesions. These aspects of QoL have not been reported in AFA. ${ }^{3,9}$

Acne did not affect choice of clothes worn nor the use of public changing facilities. This study is about AFA on the face, a visible

Table 3. Associated factors with QoL.

\begin{tabular}{|c|c|c|c|c|}
\hline Variables & n & Quality of life & Test & p \\
\hline $\begin{array}{l}\text { Age group } \\
\quad<30 \\
\quad 30-39 \\
\quad \geq 40\end{array}$ & $\begin{array}{l}21 \\
24 \\
11\end{array}$ & $\begin{array}{l}8.0 \pm 4.1 \\
6.4 \pm 3.6 \\
4.4 \pm 2.3\end{array}$ & $3.643^{* *}$ & 0.033 \\
\hline $\begin{array}{l}\text { Educational status } \\
\text { Primary/ Secondary } \\
\text { Tertiary }\end{array}$ & $\begin{array}{c}7 \\
49\end{array}$ & $\begin{array}{l}6.9 \pm 4.2 \\
6.6 \pm 3.7\end{array}$ & $0.199 *$ & 0.843 \\
\hline $\begin{array}{l}\text { Anatomical sites } \\
\text { Face only } \\
\text { Face and other sites }\end{array}$ & $\begin{array}{l}45 \\
11\end{array}$ & $\begin{array}{l}6.6 \pm 3.7 \\
6.5 \pm 4.1\end{array}$ & $0.131^{*}$ & 0.896 \\
\hline $\begin{array}{l}\text { Post inflammatory hyperpigmentation } \\
\text { Yes } \\
\text { No }\end{array}$ & $\begin{array}{c}48 \\
8\end{array}$ & $\begin{array}{c}7.2 \pm 3.7 \\
3.0 \pm 1.41\end{array}$ & $5.719 *$ & $<0.001$ \\
\hline $\begin{array}{l}\text { Presence of scarring } \\
\text { Yes } \\
\text { No }\end{array}$ & $\begin{array}{c}49 \\
7\end{array}$ & $\begin{array}{l}7.1 \pm 3.7 \\
3.1 \pm 1.5\end{array}$ & $5.120^{*}$ & $<0.001$ \\
\hline $\begin{array}{l}\text { Family history of acne } \\
\text { Yes } \\
\text { No }\end{array}$ & $\begin{array}{l}29 \\
15\end{array}$ & $\begin{array}{l}6.0 \pm 3.7 \\
6.1 \pm 3.7\end{array}$ & 0.062 & 0.951 \\
\hline
\end{tabular}

$\mathrm{NB}^{* *}=\mathrm{F}$ test. ${ }^{*}=$ Student 't' test.NB: patients not aware of family history of acne were excluded from the analysis 
part of the human anatomy. The aim of this study was not the use of make-up in order to cover acne lesions. The answer to this question would have been more relevant to the behavior of acne patients in public places than questions on choice of clothing as acne is on the face, an area where clothes are usually not worn on. In consonance with our study Gupta et al. did not find acne to influence the choice of clothing. ${ }^{6}$

Personal relationships with the opposite sex and social event attendance was negatively impacted by AFA in almost half the participants. Embarrassment from the acne was recorded in a high percentage of the participants. More than half of the study population were single. Having acne on the face may have negatively affected dating. Contrary to this study, in the United States of America, a decreased social functioning was not reported following QoL study in AFA patients. ${ }^{3}$ The differing study report maybe due to a difference in social behaviors and expectations between the two countries of study.

Significantly associated factors for QoL impairment were age, $\mathrm{PIH}$ and presence of acne scar. Marital status, level of education, age at onset, acne being on the face only, severity of acne and duration of acne did not affect QoL. A younger age $(<30$ years) was associated with a worse QoL. Majority of our study participants were single and had reported problems with having relationships with the opposite sex because of acne. This is also, the socially active age group. Unlike our study Richter et al. found no impact of on QoL in their study of QoL and treatment of AFA. ${ }^{2}$ However, Gupta et al. reported a younger age to have a worse effect on QoL like our study. ${ }^{6}$

The presence of acne scar was associated with QoL impairment. The presence of acne scar on the face leads to an unsatisfactory perception of appearance. Xiao et al. following a study on facial acne scar and willingness to pay, found a low QoL in people who have acne scars. ${ }^{17}$ Also, people who have acne scars are perceived in poor light by the society. ${ }^{18}$ Although, these studies were not specific to AFA, they do show the effect of acne scars on QoL.

Another factor that affected QoL negatively was PIH. Our study was conducted in skin of colour individuals where PIH can create an obvious contrast to background skin. The face cannot be hidden. França et al. and Darji et al. in their studies of QoL and $\mathrm{PIH}$ found that QoL was worse in individuals who had acne and PIH compared to those who have only acne. ${ }^{7,8}$

Marital status was not found to influence QoL. The lack of effect of marital status on QoL is difficult to explain as most of the study participants were single and we expected a worse QoL in them because of the reduced social function admitted by the participants. Studies of QoL in AFA are few making comparison of studies difficult. Gupta et al. in their study which was not specifically in AFA but using the CADI reported similar to this study a lack of effect of marital status on acne. ${ }^{6}$

Majority of the participants in this study had a tertiary level of education. However, level of education was not found to affect QoL. This shows that, QoL impairment has nothing to do with level of education but rather the presence of acne. Other studies of acne QoL did not assess the effect of level of education QoL making comparison difficult. ${ }^{3,9}$ Quality of life impairment was independent of anatomical location of acne. We feel that, this lack of influence of anatomical site is because acne was present on the face in both those who had it on the face and those who had extra facial involvement. Anatomical location has not been found to affect QoL in acne by other authors. ${ }^{6}$

Severity of acne was not found to affect QoL. Thus QoL affectation is independent of the severity of acne. Rather, it's the presence of acne which affects QoL and this lack of effect of severity on QoL was also documented by Richter et al. and Gupta et al. in their studies of acne. ${ }^{2,6}$ Furthermore, the women had reported appearance of the face as their main concern.

Age at onset and duration of acne were not found to affect QoL in this study despite acne being present for more than 5 years in most of the participants. Over half the participants had a teenage onset of acne and this had no effect on QoL. This maybe because the participants had become used to their acne. Studies from India and the US in consonance with our study did not find age at onset to affect QoL. ${ }^{2,6}$ Similar to this study, duration of acne was not found by Gupta et al. to affect QoL. ${ }^{6}$

A family history of acne was not found to affect QoL similar to the study by Gupta et al. ${ }^{6} \mathrm{~A}$ family history of acne is reported to be high and contributory in AFA. ${ }^{6}$ We opine that, this factor did not affect QoL because, these women were used to seeing family members with acne and in the family setting, there is no ridiculing nor embarrassment nor derogatory comments.

This study was limited by it being a one-center study and the few number of patients that were available to study.

In conclusion, QoL is impaired in AFA who have acne. This impairment is worse in the younger women, in women who have acne scars especially post inflammatory hyperpigmentation. Marital status, a family history of acne, level of education and age at onset do not affect QoL in AFA. Specific items affectated on the CADI are questions about: perception of how bad pimples were, feelings about appearance of skin, and aggression, frustration and embarrassment.

\section{References}

1. Dreno B. Treatment of adult female acne: a new challenge. J Eur Acad Dermatol Venerol 2015;29s5:14-9.

2. Richter C, Trojahn C, Hillmann K, et al. Sensitivity to change of the dermatology life quality index in adult females with facial acne vulgaris: a validation study. J Eur Acad Dermatol Venerol 2017;31:169-74.

3. Tanghetti EA, Kawata AK, Daniels SR, et al. Understanding the burden of adult female acne. J Clin Aesthet Dermatol 2014;7:22-30.

4. Ramos-e-Silva M, Ramos-e-Silva S, Carneiro S. Acne in women. Brit J Dermatol. 2015;172:20-6.

5. Holzmann R, Shakery K. Postadolescent acne in females. Skin Pharmacol Physiol 2014;27s1:3-8.

6. Gupta A, Sharma YK, Dash KN, et al. Quality of life in acne vulgaris: Relationship to clinical severity and demographic data. Indian J Dermatol Venereol Leprol 2016;82:292-7.

7. Darji K, Varade B, West D, et al. Psychosocial impact of postinflammatory hyperpigmentation in patients with acne vulgaris. J Clin Aesthet Dermatol 2017;10:18-23.

8. França K, Keri J. Psychosocial impact of acne and postinflammatory hyperpigmentation. An Bras Dermatol 2017;92:505-9.

9. Skroza N, Tolino E, Mambrin A, et al. Adult acne versus adolescent acne. J Clin Aesthet Dermatol 2018;11:21-5.

10. Ogedegbe EE, Henshaw EB. Severity and impact of acne vulgaris on the quality of life of adolescents in Nigeria. Clinical, Cosmetic and Investigational Dermatology 2014:7:329-34.

11. Anaba EL, Adebola OO. Quality of life of adolescents with facial acne vulgaris before and after treatment in Ibadan, Nigeria. Int J Res Dermatol 2019;5:155-9.

12. Tan JKL, Tang J, Fung K, et al. Development and validation of a Comprehensive Acne Severity Scale (CASS). J Cutan Med Surg 2007;11:211-6. 
13. Finlay AY. Cardiff Acne Disability Index. Accessed: 1/11/2017. Available from: https://www.cardiff.ac.uk/medicine/resources/quality-of-life-questionnaires/cardiff-acne-disability-index

14. Motley RJ, Finlay AY. Practical use of a disability index in the routine management of acne. Clinical Experimental Dermatol 1992;17:1-3.

15. Walker N, Lewis-Jones MS. Quality of life and acne in Scottish adolescent school children: use of the children's dermatology life quality index and the cadiff acne disability index.
J Eur Acad Dermatol Venereol 2005;20:45-50.

16. Di Landro A, Cazzaniga S, Cusano F, et al. adult female acne and associated risk factors: results of a multicenter case-control study in Italy. J Am Acad Dermatol 2016;75:1134-41.

17. Xiao Y, Chen L, Jing D, et al. Willingness-to-pay and benefitcost analysis of chemical peels for acne treatment in China. Patient Preference Adherence 2019;13:363-70

18. Dreno B, Tan J, Kang S, et al. How people with facial acne scars are perceived in society: an online survey. Dermatol Ther (Heidelb) 2016;6:207-18. 